Article

\title{
Effects of Different Bamboo Forest Spaces on Psychophysiological Stress and Spatial Scale Evaluation
}

\author{
Wei Lin, Qibing Chen *, Xiaoxia Zhang, Jinying Tao, Zongfang Liu, Bingyang Lyu $₫$, Nian Li, \\ Di Li and Chengcheng Zeng $(\mathbb{D}$ \\ College of Landscape Architecture, Sichuan Agricultural University, Chengdu 611130, China; \\ landscape1990@163.com (W.L.); zhangxiaoxia6228@163.com (X.Z.); taojinying666@163.com (J.T.); \\ liuzongfang666@163.com (Z.L.); beyonglv@163.com (B.L.); nli@sicau.edu.cn (N.L.); frank0707@126.com (D.L.); \\ zcclandscape@163.com (C.Z.) \\ * Correspondence: cqb@sicau.edu.cn; Tel.: +86-0288-265-2175
}

Received: 10 May 2020; Accepted: 28 May 2020; Published: 1 June 2020

\begin{abstract}
Forests are large-scale green space resources that may exert a positive impact on human physiology and psychology. Forests can be divided into mixed forest and pure forest, according to the number of dominant tree species. Pure forest offers specific advantages for the study of spatial structure and scale. In this study, a type of pure forest (i.e., bamboo forest) was adopted as a research object to investigate differences in the physiological and psychological responses of psychologically pressured college students to different types of forest space. We recruited 60 participants and randomly assigned them to three experimental groups: forest interior space (FIS), forest external space (FES) and forest path space (FPS). All participants were asked to perform the same pre-test task but different post-test tasks. The pre-test involved performing a pressure-inducing task, whereas the post-test involved viewing photographs of each space type. The same indicators were measured in both the pre- and post-test, including a $\beta / \alpha$ index from each lobe, positive emotion, negative emotion and total mood disturbance (TMD) values, according to the profile of mood states (POMS), in addition to spatial scale preferences obtained through a questionnaire and interviews. We analysed brain waves and mood indicators through analysis of covariance (ANCOVA), whereby the FES group exhibited the best physiological and psychological relaxation effect. The FPS group displayed a medium effect, and the FIS group exhibited the worst effect. Analysis of variance (ANOVA) was used to analyse the spatial scale scores. The FPS and FES types achieved a higher spatial scale preference scores than the FIS type. Based on a comparison of the psychophysiological results with the spatial scale preference results, spatial structure and scale are considered to be important intrinsic factors that influence the health effects of pure forest. The results can provide guidance for forest-related human health activities and their management.
\end{abstract}

Keywords: bamboo forest; psychophysiological stress; forest spatial scale

\section{Introduction}

With the development of cities and villages, the relationship between human beings and green land is also changing. In dense urban areas, human beings are primarily exposed to small- and medium-sized urban green spaces [1-3], while in non-urban areas, humans have the opportunity to fully integrate into large natural green spaces. Forests are valuable large-scale green space resources that can be divided into mixed forest and pure forest. Mixed forest consists of two or more species, whereas pure forest consists of primarily one species. Most mixed forests are not plantations but are formed naturally over a long period of time. In certain respects, mixed forest has advantages over pure 
forest. For example, mixed forest is more effective than pure forest in improving regional microclimate, increasing forest material reserves, and promoting material circulation and landscape diversity [4-6]. However, mixed forest is greatly inferior to pure forest in terms of economic efficiency and growth rate, particularly in countries and regions with urgent development needs. For developing regions that must rapidly transform their environments and increase their forest resources, pure forest is undoubtedly a better choice. For example, China's reforestation programme, a national effort underway since the beginning of the last century, is $90 \%$ pure forest.

However, faced with a large amount of pure forest, many countries and regions, including China, are further considering the scientific use of such forests. Forests are important ecological environments and resources that provide not only ecological and economic benefits, but also important health benefits. Many urban residents benefit from forest tourism and forest therapy activities. Studies on forest health benefits typically focus on physiological and psychological indicators to confirm the impact of forests on the human body $[7,8]$.

The health benefits of forests have been confirmed by researchers, particularly with respect to mixed forests [9-12]. In recent research on the physiological and psychological effects of forests, mixed forest studies focus more on the effects of plant diversity and forest elements. Species within pure forests are relatively homogenous, so there is little variation in plant diversity or elements for most pure forest spaces, and, thus, plant diversity and forest elements may not reflect the primary inherent causes of the health effects of pure forests [13]. However, this characteristic of pure forest facilitates studying the effect of forest spatial structure. This study aims to investigate the health effects of pure forest of differing spatial type and scale.

\subsection{Forest Health Benefits and the Effect of Forest on Physiological and Psychological Stress}

Numerous studies have shown there is a close relationship between the health benefits of forests and human physiological and psychological responses. Studies by Lee et al. have shown that individuals suffering from illness can strengthen their immune systems and benefit in other ways through long-term forest therapy [14]. Chen et al. noted that short-term forest activities, such as walking or sitting, can reduce physical and psychological stress and improve attention and cognitive ability [9]. Hassan et al. conducted a bamboo forest activity experiment on individuals suffering from stress, and found that these individuals exhibited signs of physiological relaxation, such as reduced blood pressure and increased $\alpha$ waves (a type of brain wave that indicates relaxation), as well as signs of psychological and emotional relaxation [15]. A large number of studies have used photographs of forests as stimulus sources. For example, studies by Chiang et al. showed that the forest environment had positive effects on, e.g., brain waves, emotions and attention, when participants were shown photos of forests for 5-20 min [9,16]. In brief, previous studies have shown that the health benefits of forests are reflected in psychological indicators, such as mood and cognition, as well as physiological indicators, such as blood pressure, heart rate variability and brain waves.

Physiological and psychological stress is a daily health concern for today's youth. Forest activities or forest viewing can provide relief from stress. This study focuses on a youth population of college students by considering psychological stress, as assessed with the profile of mood states (POMS) questionnaire [17], and physiological stress, as assessed according to brain waves [18,19], both of which are commonly used indicators in previous studies. There are many types of brainwave indicator, such as single indices $(\theta, \alpha, \beta)$ and index ratios $(\theta / \beta, \beta / \alpha, \theta /(\alpha+\beta),(\alpha+\theta) / \beta,(\alpha+\theta) /(\alpha+\beta))$ [20]. This study used the $\beta / \alpha$ index ratio ( $\beta$ waves are associated with alertness, while $\alpha$ waves are associated with relaxation) as a brainwave indicator to describe the level of physiological stress. The $\beta / \alpha$ index has been considered to possess good evaluation value in previous studies [21,22]. The higher the $\beta / \alpha$ is, the more nervous the subject. Conversely, the lower the index is, the more relaxed and calm the subject. In previous studies, the POMS questionnaire has been used to assess psychological stress [16]. One of the questionnaire's advantages is its easy-to-understand content. In addition, the POMS questionnaire has 
multiple subscales, enabling one to assess subject emotions in multiple dimensions and then aggregate them into "positive mood", "negative mood" and "total mood disturbance" (TMD).

\subsection{Spatial Scale Effects and Space Types of Pure Forest}

A change in spatial scale causes changes in other factors in a space, such as sound, temperature and humidity, as well as light. Watts et al. noted that sound in a landscape space is correlated with the degree of anxiety of the perceiver [23]. Krzywicka found that people have different preferences for sounds in landscape space [24]. The relationship between space and the human body has been studied in the fields of environmental behaviour, architecture and landscape science, as well as in their intersections. Scholars in the field of architecture and urban planning have found that spatial structure influences the physiological and psychological responses of individuals in the environment through various aspects, such as scale, stimulus approaches and location relations. Jan Gehl suggested that the spatial structure determines function and further influences the activities of the individuals in the space. He also noted that space is divided into centralized and dispersed space and can be understood as centripetal and centrifugal [25]. According to Edward Hall's theory, the three-dimensional scale of space influences people's feelings. Hall proposed four types of spatial distance in human communication [26]. Bryan Lawson noted that space is stimulating to the human body and that two-thirds of the human perception of space comes from vision [27]. Such findings suggested to us that spatial scale might have an impact on the health benefits of forest viewing.

The proportion of the dominant tree species in pure forest is typically more than $90 \%$, so the structure of the pure forest can be regarded as a space created by repeated individual trees, but on different scales. This phenomenon is important and makes such forests a suitable object through which to study the relationship between spatial scale and health benefits. In Chiang et al.'s study, forest space was classified by location into external space, internal space and edge space. This classification scheme was created for a mixed forest, and based on obvious biodiversity differences among the three locations. The biodiversity within the pure forest is relatively uniform, but the spatial structure of individual locations in the forest differs, primarily in terms of three-dimensional scale and plant density. Thus, this paper aims to determine whether different locations (representing different spatial types and scales) produce different physiological and psychological effects. The spatial types of pure forest can be expressed by models. Three basic spatial types of pure forest are summarized in this study based on the relationship between the viewer and the forest (Figure 1a-c). Forest interior space (FIS) is a space that consists entirely of repeated dominant trees. In this space, the viewer perceives little change in the vegetation landscape. Forest path space (FPS) is a corridor space formed in the forest for artificial or other reasons, whereby the width of the corridor is larger than the average spacing in the forest. The viewer in the corridor interval can feel an obvious sense of direction and guidance. Forest external space (FES) can be understood as the space between separate patches of forest. This spacing between patches is much larger than the average spacing within the forest, and the viewer does not feel a sense of direction or enclosure. The three pure forest space models defined in this study are relative concepts, rather than structures with an absolute scale. 


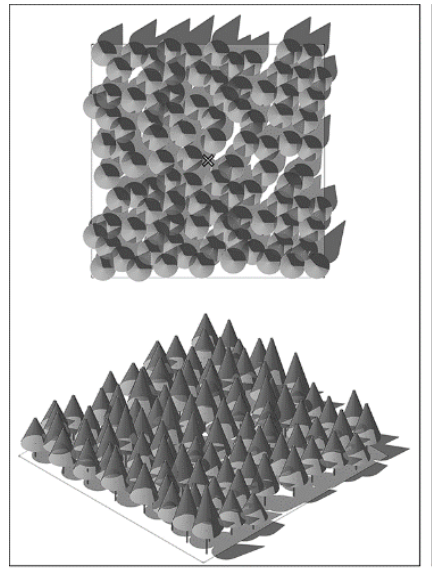

a. Forest interior space (FIS)

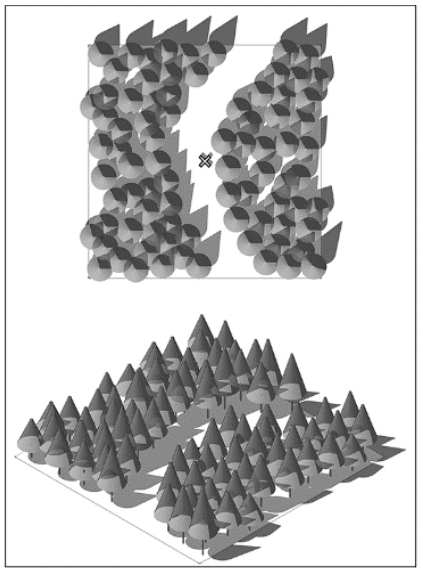

b. Forest path space (FPS)

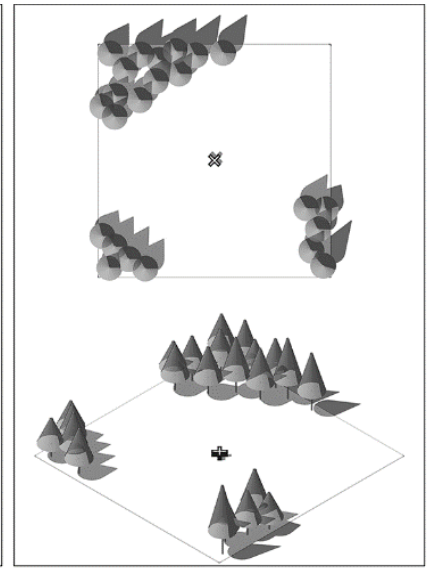

c. Forest external space (FES)
Plant site

$\bowtie$ Viewer site

Figure 1. Three types of pure forest space based on scale.

\subsection{Aims and Hypotheses}

This study uses three typical pure forest spaces (FIS, FPS and FES) as stimulus sources. The aim is to investigate differences in physiological and psychological stress, based on brain waves, emotional state and spatial scale preference scores, as they correspond to the different pure forest spaces. Subsequently, the relationship between the two aspects is discussed. Considering previous studies and other greenbelt-related research, we propose the following hypotheses.

Hypothesis 1 (H1). FPS may produce better physiological and psychological responses, including emotional states and brain waves, followed by FIS. The worst responses are produced by FES.

Hypothesis 2 (H2). In terms of spatial scale, FPS and FIS may be more popular than FES.

\section{Materials and Methods}

\subsection{Stimuli Selection}

There are many types of pure forest and it is impossible to study all types simultaneously, so this experiment focuses on the bamboo forest. The bamboo forest is a type of pure forest widely found in China. China has a long history of planting bamboo, and the Chinese are familiar with bamboo forests. According to the previous classification basis and our field survey, bamboo forest space can be divided into three categories: forest interior space (FIS), forest external space (FES) and forest path space (FPS) (Figure $2 \mathrm{a}-\mathrm{c}$ ). The three spaces are distinguished based on their location in the forest and have obvious difference in spatial scale. However, in actual situations, the bamboo forest is continuous, and the spatial type is gradually transitive. The space in a transitional zone may exhibit characteristics of two types of space simultaneously. In the sample selection, we avoid this type of space to ensure that each type is distinct from the others. No people appear in the sample photographs, which represent the pure forest space in nature.

In this study, space samples were created using photography. The act of viewing photographs has been shown to produce brain wave responses, and such responses to photographs as stimulus sources have been used as emotional indicators in many studies [7,18]. To assemble a diverse set of samples, we photographed 15 bamboo forest areas in four provinces (Sichuan, Chongqing, Yunnan and Guizhou) in Southwest China. Approximately 100-150 original photos were taken of each space type and ranked according to quality, representativeness and objectivity. Ultimately, 30 photographs were selected for each type to form 3 groups of 90 photographs in total. All photos were taken on sunny days with the same equipment and shooting parameters, including aperture and shutter speed. 


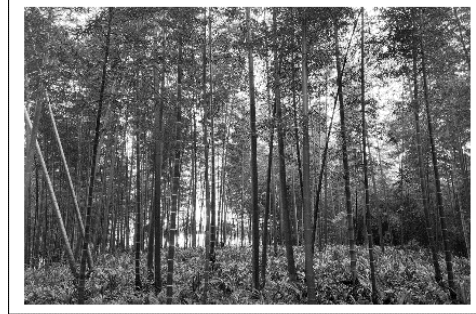

a. Photo samples of FIS

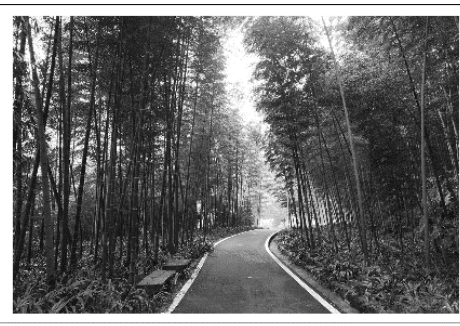

b. Photo samples of FPS

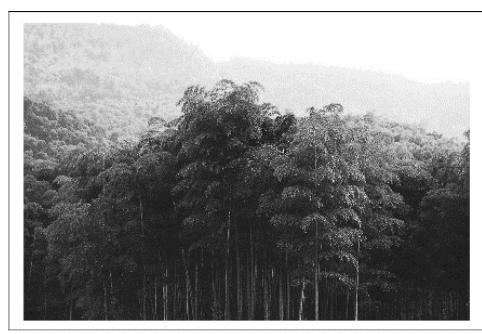

c. Photo samples of FES

Figure 2. Photo samples of three bamboo forest spaces.

\subsection{Participants}

We recruited 60 college students through posters placed around campus. Of the participants, $45 \%$ were male, and $55 \%$ were female. The study subjects were mostly from Southwest China, and all were confirmed to have a cognitive bias for bamboo forest during recruitment. Through the State-Trait Anxiety Inventory (STAI) and interviews, we determined that the subjects were experiencing learning pressure. Previous studies have noted that professionals and non-professionals perceive space differently. We intended for our research subjects to represent the general population. Therefore, students majoring in landscape architecture and forestry were not selected. The subjects had an average age of 20.6 years (range $=18$ to $24, \mathrm{SD}=2.92$ ), no history of smoking or mental illness and a body mass index (BMI) in the normal range (range $=18.5$ to 23.9 ). All subjects were fully informed regarding purpose of the study prior to the experiment and voluntarily provided their informed consent to participate.

\subsection{Measurements}

\subsubsection{Physiological Stress}

The measurement instrument we used was the Emotiv EPOC+ EEG headset, which is a harmless, non-invasive device. The reliability and accuracy of the instrument have been demonstrated in previous studies $[18,19,28]$. Emotiv EPOC+ covers four brain lobe regions (i.e., the frontal lobe, temporal lobe, parietal lobe and occipital lobe) of the human brain using 14 channels (AF4, AF3, F3, F4, F7, F8, FC5, FC6, T7, T8, P7, P8, O1, O2) (Figure 3). This study analysed 8 channels in four brain lobe regions: F3 and F4 in the frontal lobe, which controls cognition, language, emotion and behaviour (F3 and F4 were selected as representatives); T7 and T8 in the temporal lobe, which controls audio-visual memory and language processing; P7 and P8 in the parietal lobe, which controls sensory connection and reception; and $\mathrm{O} 1$ and $\mathrm{O} 2$ in the occipital lobe, which controls all visual information.
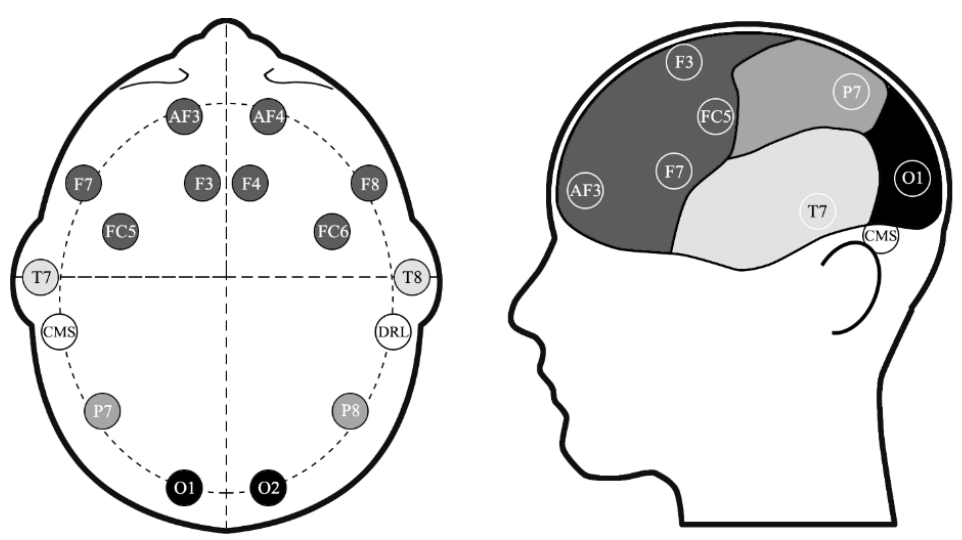

Frontal lobe

Temporal lobe

Parietal lobe

Occipital lobe

(MS) (DRI) Reference points

Figure 3. Areas of the four brain lobes and the positions of the 14 channels. 


\subsubsection{Psychological Stress}

This study assessed psychological stress by measuring mood state. Mood state was measured using a Chinese version of the POMS adapted from Z. Beili [17]. The POMS consists of seven mood subscales: tension, anger, depression, fatigue, vitality, confusion and self-esteem. The POMS has 40 questions, and each subscale includes 6-7 questions on mood states. Each question was answered on a five-point scale ranging from 0 (none at all) to 4 (a lot). Three indicators were used in the analysis: positive mood (vitality + self-esteem), negative mood (tension + anger + depression + fatigue + confusion) and total mood disturbance (TMD) (negative mood-positive mood +100 ).

\subsubsection{Spatial Scale Score}

The spatial scale represents an impression for humans. It includes not only the overall subjective feeling, but also several major specific scale indicators. To evaluate such matters, a spatial scale questionnaire and interviews were adopted. According to previous theories, the three-dimensional scale and density of a space have an important impact on feelings. Therefore, we adopted a spatial scale consisting of five parts: width, height, distance, density and overall. Width represents the perception of the horizontal field of view within the scope of the image. Height indicates the vertical visual field perception and the height of the plants in the image. Distance represents frontal visual perception within the scope of the image. Density represents the feeling of plant density in the image. Overall represents the subjective feeling regarding the entire space within the scope of the image. Each part was scored on a five-point Likert scale from 0 (none at all) to 4 (a lot). Finally, the score for the five individual parts was added to obtain a total score for spatial scale. Before the participants viewed the pictures, we explained the meanings of the five parts and the corresponding diagrams (Figure 4).

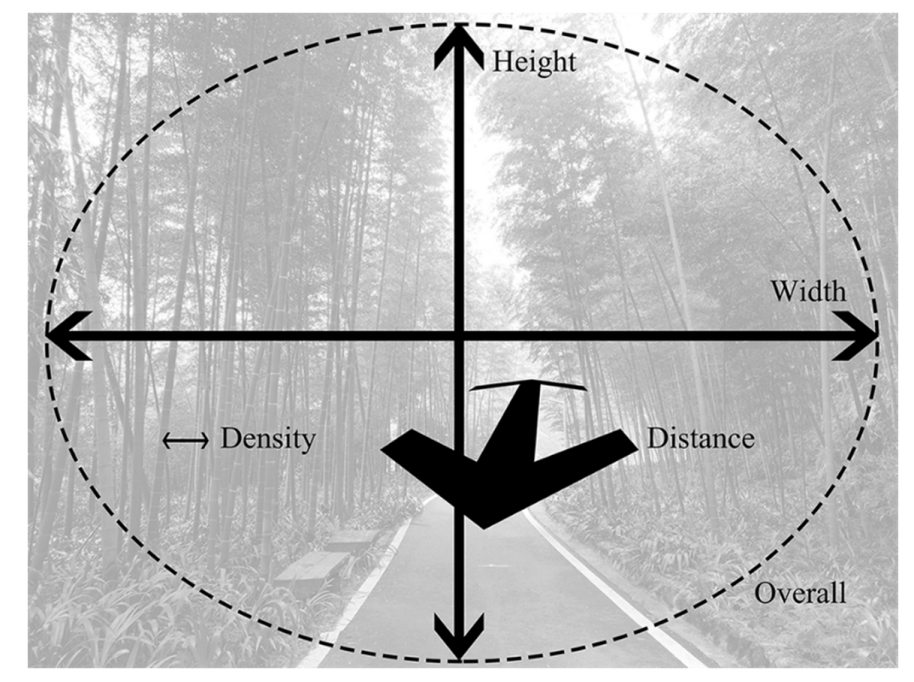

Figure 4. Five parts of the spatial scale in the bamboo forest space.

\subsection{Procedure}

The experiment was conducted in May 2019 in a university classroom $\left(103^{\circ} 51^{\prime} 39^{\prime \prime} \mathrm{E}, 30^{\circ} 42^{\prime} 22^{\prime \prime} \mathrm{N}\right.$, $512 \mathrm{~m})$. The indoor temperature, air humidity and light intensity were maintained at $22{ }^{\circ} \mathrm{C}, 60 \%$ and 520 lux, respectively. The sixty subjects were randomly divided into 3 groups, and all subjects completed the pre- and post-test. After entering the classroom, the subjects donned the EEG devices under the guidance of research project staff, and the entire experiment process and requirements were re-explained. The pre-test consisted of a 10-min high-pressure task, in which the subjects were asked to complete a series of multi-digit mental arithmetic multiplication and division problems within a given time period. The physical and psychological fatigue and stress of the subjects were expected to increase after they completed the pressure-inducing task [29,30]. All three groups underwent the same pre-test, 
during which the EEG device recorded the brainwave data of the subjects. At the end of the pre-test, the subjects completed the POMS. Pre-test data, including the brainwave data ( 8 channels) and 1 POMS data set from each group were collected and used as covariance (baseline) data for statistical analysis.

The post-test involved viewing photographs (colour) of a bamboo forest space from a viewing distance of $4 \mathrm{~m}$. The photos were shown using a projector. Prior to the post-test, the research project staff confirmed the equipment was operating properly. Each group viewed 30 photos of a bamboo forest space randomly for $15 \mathrm{~s}$ each. The entire post-test process lasted $10 \mathrm{~min}$. After the post-test, the subjects completed the POMS and a spatial scale questionnaire, and interviews were conducted. Post-test data, including the brainwave data ( 8 channels), 1 POMS data set and 5 spatial scale data sets from each group, were collected for statistical analysis. All the EEG data were continuously recorded by Emotiv EPOC+ and averaged for $10 \mathrm{~min}$ after the measurement.

According to previous studies, the physiological effects of environmental stimuli occur after $4 \mathrm{~min}$ [31,32], and psychological effects through vision occur after $5 \mathrm{~s}$ [31]. Therefore, the 10-min preand post-tests could effectively collect physiological and psychological indicators. The total time of each subject in the experiment was held to within $30 \mathrm{~min}$, including the time required to don the measurement device and the interview time. The process is shown in Figure 5.

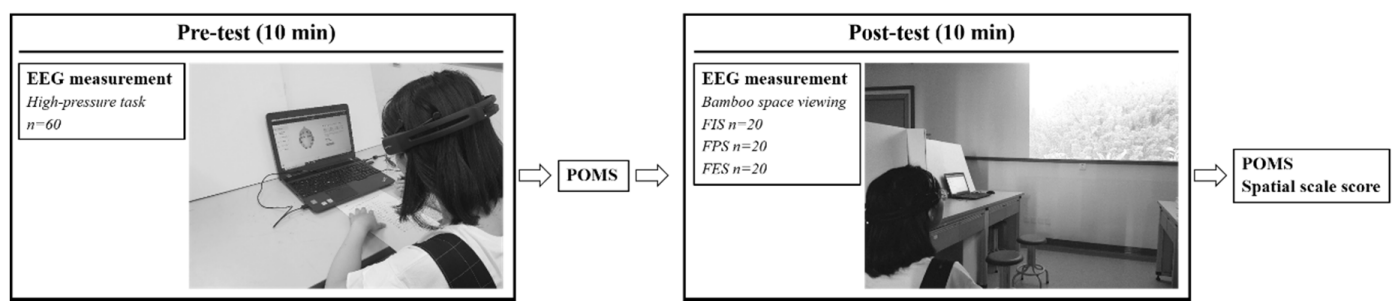

Figure 5. Study procedure (FIS = forest interior space, FPS = forest path space, FES = forest external space).

\subsection{Statistical Analysis}

In this study, ANCOVA was used to analyse physiological stress ( $\beta / \alpha$ index) and psychological stress (mood state). The ANCOVA used the pre-test results as covariates (baseline data) to eliminate the effects of different levels of individual stress. ANOVA was used to analyse the spatial scale scores. SPSS 22.0 software was used for all analyses.

\section{Results}

\subsection{Effects of Bamboo Forest Space on Physiological Stress}

To observe the effects of a bamboo forest space on physiological stress among the three groups, we applied ANCOVA to the post-test EEG indicators ( $\beta / \alpha$ index) across the groups (the pre-test results were the covariates). We found four channels (T7, P7, O1, O2) had significant effects. The T7 channel, P7 channel, O1 channel and O2 channel indicated the significantly lowest $\beta / \alpha$ index in the FES group $(\mathrm{M}=1.474,0.761,0.954$ and 1.005) and the highest $\beta / \alpha$ index in the FIS group $(\mathrm{M}=2.503,2.121,1.69$ and 1.495). The all eight channels revealed the lowest $\beta / \alpha$ index was in the FES group and the highest values were in the FIS group (Figure 6). The ANCOVA results corresponding to the EEG $(\beta / \alpha$ index) are presented in Appendix A (Table A1). 


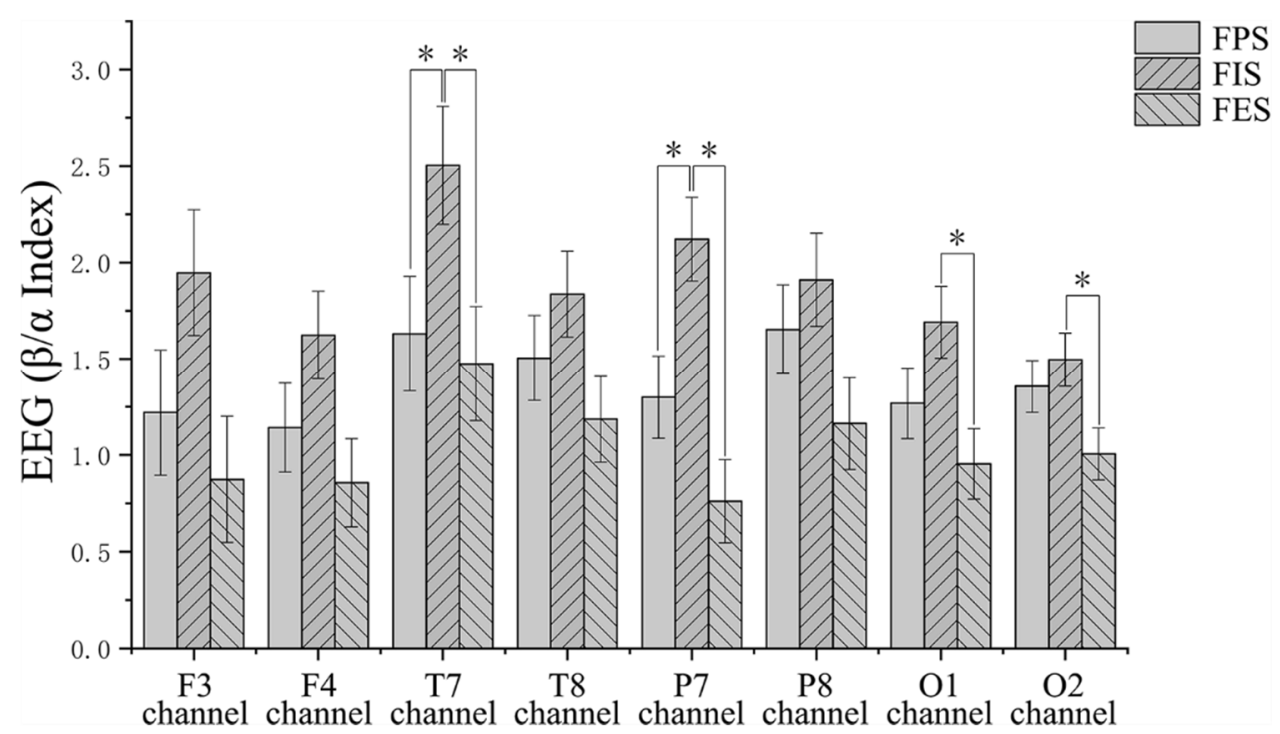

Figure 6. EEG $(\beta / \alpha$ index $)$ values among the three groups $\left(N=20\right.$; mean \pm standard error; ${ }^{*} p<0.05$; ** $p<0.01)$.

\subsection{Effects of Bamboo Forest Space on Psychological Stress}

ANCOVA was also used to analyse the post-test mood state indicators across the groups (the pre-test results were the covariates). Positive mood and TMD showed significant effects. The positive mood of the FES group $(M=13.92)$ was significantly higher than that of the FPS group ( $M=9.104)$. The TMD of the FES group $(M=92.993)$ was significantly lower than that of the FIS group $(M=99.548)$. Although the results for negative mood were not significant, the FES group had the lowest score of the three groups, which indicates a better outcome (Figure 7). The ANCOVA results corresponding to the mood state are presented in Appendix A (Table A2).

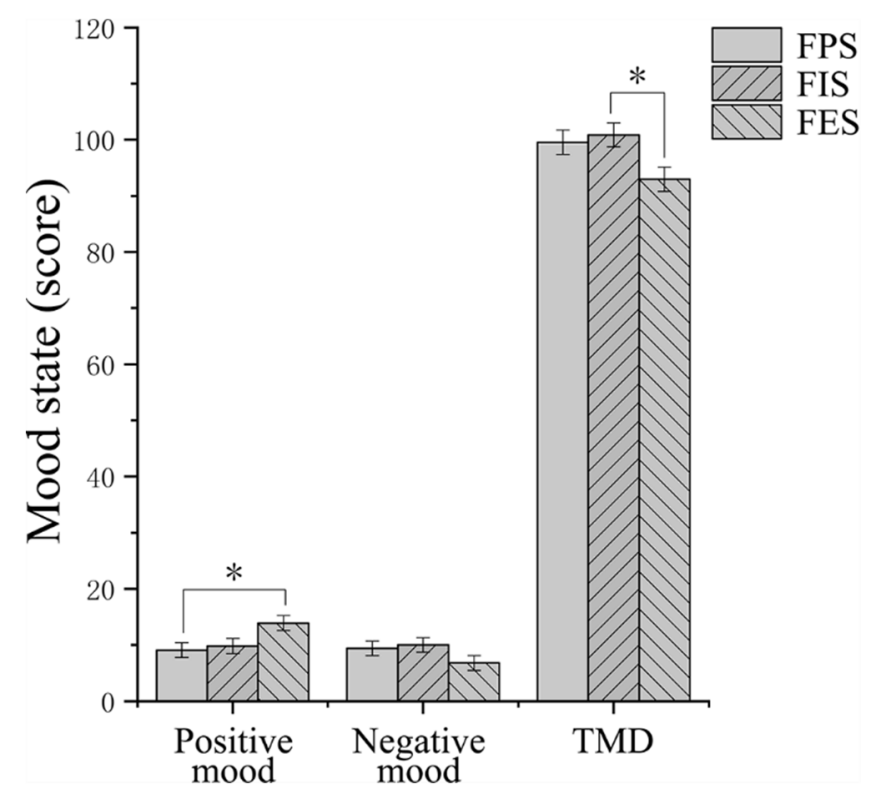

Figure 7. Mood state values among the three groups $\left(N=20\right.$; mean \pm standard error; ${ }^{*} p<0.05$.

\subsection{Spatial Scale Scores for Bamboo Forest Spaces}

The evaluation of spatial scale in this study was based on a questionnaire and interviews. The information gathered in the interviews was used as an aid to the discussion. We applied ANOVA to the total and sub-part scores for spatial scale across the groups. The scores for "overall", "width" 
and "density" were significantly higher in the FPS group ( $\mathrm{M}=12.90,2.50$ and 2.45) and the FES group $(\mathrm{M}=13.40,3.20$ and 2.60). The scores for the same parts were significantly lowest in the FIS group $(\mathrm{M}=9.70,1.75$ and 1.35). The scores for the other parts were similar but were not significant (Figure 8). The ANOVA results corresponding to the spatial scale questionnaire are presented in Appendix A (Table A3).

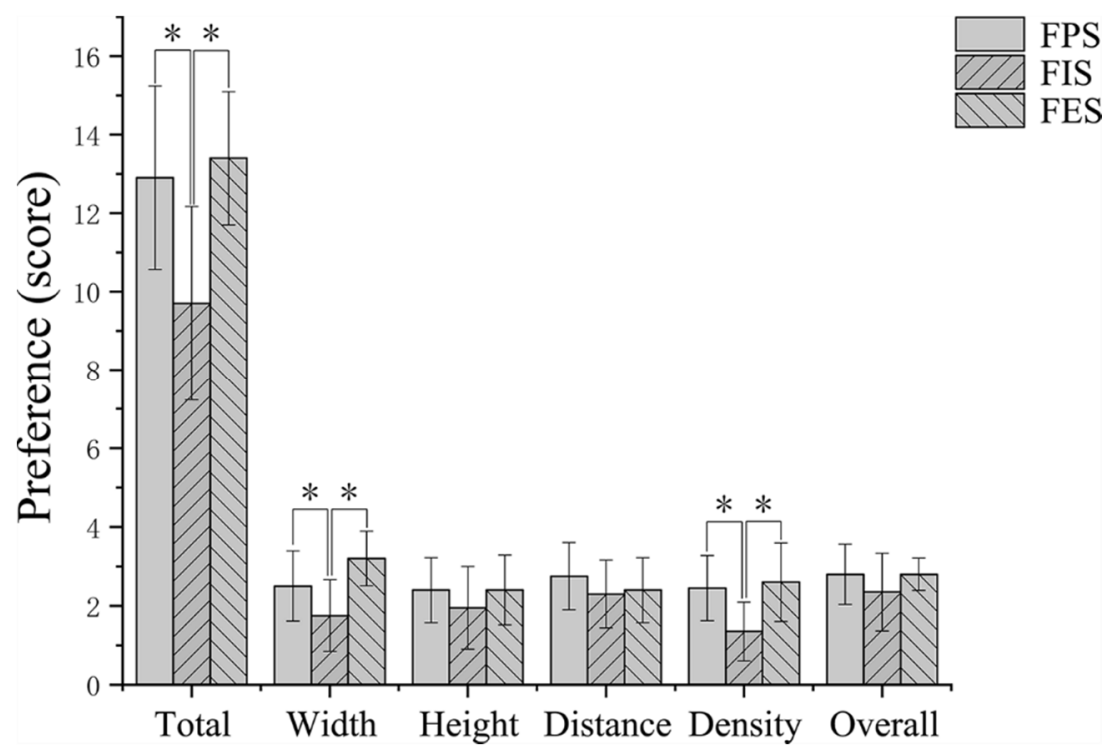

Figure 8. Spatial scale questionnaire scores among the three groups $(N=20$; mean \pm standard error; ** $p<0.01)$.

\section{Discussion}

\subsection{Does Bamboo Forest Space Affect Physiological and Psychological Stress?}

There were significant differences between the pre-test and post-test values of certain physiological and psychological indicators. As we have noted, there is little difference in plant diversity between different locations in pure forest. Thus, obviously, the differences between the physiological and psychological indicators have little relationship with plant diversity. At the same time, the spatial structure of pure forests represents an important intrinsic factor that affects physiological and psychological responses and, thus, reflects the health benefits of the pure forest. Related theories of spatial structure note that people have the ability to perceive space and that different factors of the spatial structure, such as scale and shape, influence emotion and behaviour [26,27]. Jan Gehl proposed that people have a "sense of place", which is a physical and mental pleasure that originates in feelings regarding spatial elements [25]. Therefore, one can speculate that among the three types of space considered in this study, certain spaces would be better able to stimulate the "sense of place" of stressed youth and, thus, evoke better physiological and psychological responses.

In a study on forest location by Jiang et al., FIS was considered the most favourable based on biological diversity and the human preference for tall plants [33,34]. Additionally, numerous studies have shown that forest walking can create a sense of relaxation [35-37]. Based on previous research results, we expected the best physiological and psychological relaxation effect from FPS. Obviously, the results of this study differ from our expectations. Among all the significant results, FES performed the best, FIS produced the highest stress in the significant EEG results, and FPS exhibited the worst performance based on the significant positive mood results. We speculate that the key structural factors of pure forest space that influence psychophysiological stress are "spatial diversity" and "degree of enclosure". The difference between FPS and FIS lies in the path, and the same point presents a close sense of enclosure in the spatial structure. FES is a completely different type. Compared with the other two types of space, viewers of FES have a wider field of vision and can see more sky, as well as receive 
an overall view of the bamboo forest. The pure forest is characterized by a single variety of plant in FIS and FPS. Viewers who gaze at relatively monotonous landscapes may feel bored, which may further trigger negative mood and physiological stress. FES has background and foreground elements and colour mixing, so it is not monotonous in spatial colour and form. Thus, it is superior to the other two space types in terms of "spatial diversity" and has a lower "degree of enclosure".

Previous studies on the mixed forest have suggested that forest interior space with higher biodiversity and a dense plant landscape may provide better health benefits [16,38]. These results support our conjecture that the intrinsic reasons for the psychophysiological responses to the pure forest and the mixed forest are different. Plant diversity is not the key factor in the pure forest, and different spatial structures are an important reason for the noted difference. FES has a more favourable spatial structure than FIS and FPS, with a larger field of vision, richer landscape and moderate green proportion.

\subsection{Are There Differences in the Spatial Scale Evaluation of Bamboo Forest Spaces?}

Subjective feelings form one part of the spatial scale evaluation. We extracted generic information from the interviewees, such as "I prefer the ease of the bamboo trails", "The inner space of the bamboo forest has a sense of limitation", "The internal space of the bamboo forest is more chaotic and depressing", "The external view is more comfortable and tidy" and "I like the orderly bamboo landscape". Based on the information gathered in the interviews, we believe that the key factors related to the spatial scale preference for bamboo forests are "visibility" and "tidiness". This finding differs from previous research suggesting that people prefer to be surrounded by green forests and to be close to nature $[39,40]$. In this study, due to high density and a lack of management, FIS tended to cause a sense of clutter and depression, which resulted in the lowest evaluation among our subjects. Although FPS is a special type of FIS, the bamboo on both sides of the path is typically straight and orderly, shielding the unfavourable aspects of the forest. However, forward vision is not obstructed in FPS, and "visibility" is better. Therefore, the subjects produced a median evaluation for FPS. FES offers a more complete and broad view than the other two types of space. In addition, a forest landscape viewed from the outside is typically more orderly. Thus, FES received the highest evaluation among our subjects.

When we compared the spatial scale score and the interview information, we found that the two were consistent. FPS received the highest score for "distance", which suggests that FPS has good "visibility" in the front and is consistent with the "relaxed feeling on the path" noted in the interviews. FES received the highest score for "width", which indicates that the horizontal view is not constrained, which reflects the statements in the interviews to the effect that the "external view is more comfortable". However, FIS received a lower score for each item, particularly for "density", which reflects the density of FIS in three-dimensional space and recalls the participants' view that "internal space is more chaotic and depressing". In short, the spatial scale scores were basically consistent with the interview information, and they jointly reflect the subjective feelings of the stressed youth towards the bamboo forest space. FES and FPS were more highly preferred than FIS, because of the longer and wider field of view and the moderate density and the regularity of plants.

The three types of bamboo forest considered in this study have different three-dimensional indices and densities. Both the questionnaire scores and the interviews indicate that the subjects evaluated the spatial scales of bamboo forest differently. Generally, they had the highest spatial preference for FES, which also had the most relaxing physiological and psychological effect. FPS was in the middle, and FIS was the worst in both aspects. The psychophysiological indices and spatial preferences were basically consistent, which suggests that the spatial structure and the scale of pure forest are the underlying reasons for their health benefits. 


\subsection{Limitations and Future Research}

This study investigated the different psychophysiological effects of three types of bamboo forest space on youth under pressure, and the spatial scale evaluation these types of space received. It should be acknowledged that the potential conditions or psychological state of individuals may have some impact on the results of the study, which should be verified with a larger population in the future. Other types of pure forest and other populations would be worthwhile studying. Additionally, future studies could examine more spatial structure indicators, such as spacing, crown width and tree diameter at breast height, and quantify these indicators with further elaboration of the effects of different spatial scales of the pure forest. This study also compared the spatial scale results with the results for the psychophysiological indicators and discussed the intrinsic causes of the health effects of the pure forest, whereby certain results differed from those found in previous studies on the mixed forest. We conclude that these differences are caused by differences in spatial characteristics between the pure and mixed forest. However, there is a lack of comparative evidence for these two forest types. In future research, we will further study the differences in space and health benefits between the pure forest and mixed forest.

\subsection{Application}

This study shows that an appropriate spatial structure and scale are highly important to the health benefits of pure forest. The external spatial landscape and path landscape of the bamboo forest are conducive to physical and psychological relaxation, and received higher evaluations with respect to spatial scale. Therefore, in the regional planning of bamboo forests, targeted tourism layouts can be designed, such as by assigning the tourism function to the external areas of the forest and consigning forestry production to the forest's interior. In addition, the rationality of the spatial structure of pure forest is an important factor that affects physiology and psychology. In the construction of a bamboo forest landscape, higher, larger and more orderly plants, wider vistas and medium density could improve the health benefits of the landscape.

\section{Conclusions}

The health benefits of large-scale forest green space require more in-depth research and scientific examination. This study focused on the effect of a pure forest space (bamboo forest) on physiological and psychological responses and spatial scale preferences. We used photographs of three spatial types of bamboo forest (i.e., FES, FPS, FIS) as stimuli, to analyse the differences among the psychophysiological indicators. We administered a spatial scale questionnaire to, and conducted interviews with, three subject groups. The results revealed that FES performed best in the area of physiological and psychological relaxation, followed by FPS and finally FIS. However, the spatial scale scores and evaluations for FES and FPS were higher than for FIS. The psychophysiological indicators were basically consistent with the spatial scale preferences, so we believe that the nature of the spatial structure is an important intrinsic reason for the difference. This study has practical value for the spatial layout of bamboo forest scenic spots and the construction of bamboo forest landscapes, and can provide guidance for pure forest management and forest therapy.

Author Contributions: Conceptualization, W.L. and Q.C.; methodology, W.L.; software, X.Z.; validation, W.L. and X.Z.; formal analysis, J.T. and Z.L.; investigation, B.L., N.L., D.L. and C.Z.; data curation, B.L., N.L., D.L. and C.Z.; writing — original draft preparation, W.L.; writing—review and editing, W.L. and Q.C.; visualization, X.Z.; supervision, Q.C.; project administration, Q.C. All authors have read and agreed to the published version of the manuscript.

Funding: This research received no external funding.

Acknowledgments: This study was undertaken with the approval of the Sichuan Agricultural University Institutional Animal Care and Use Committee, China (FJY-B20170703-3).

Conflicts of Interest: The authors declare no conflict of interest. 


\section{Appendix A}

Table A1. Effect of bamboo forest space on EEG ( $\beta / \alpha$ index) across the experimental groups (covariates: pre-tests; dependent variables: post-tests).

\begin{tabular}{|c|c|c|c|c|c|c|c|}
\hline EEG $(\beta / \alpha$ Index $)$ & Sum of Squares & df & Mean Square & $\mathbf{F}$ & Sig. & Partial $\eta^{2}$ & $\begin{array}{c}\text { Pairwise } \\
\text { Comparisons }\end{array}$ \\
\hline \multicolumn{8}{|l|}{ F3 channel } \\
\hline Pre-test & 0.129 & 1 & 0.129 & 0.061 & 0.805 & 0.001 & \\
\hline Group & 11.774 & 2 & 5.887 & 2.795 & 0.070 & 0.091 & \\
\hline Error & 117.938 & 56 & 2.106 & & & & \\
\hline \multicolumn{8}{|c|}{$R^{2}=0.096\left(\right.$ Adj $\left.R^{2}=0.047\right)$} \\
\hline \multicolumn{8}{|c|}{ F4 channel } \\
\hline Pre-test & 0.057 & 1 & 0.057 & 0.055 & 0.815 & 0.001 & \\
\hline Group & 5.974 & 2 & 2.987 & 2.885 & 0.064 & 0.093 & \\
\hline Error & 57.980 & 56 & 1.035 & & & & \\
\hline \multicolumn{8}{|c|}{$R^{2}=0.094\left(\operatorname{Adj} R^{2}=0.046\right)$} \\
\hline \multicolumn{8}{|c|}{ T7 channel } \\
\hline Pre-test & 1.208 & 1 & 1.208 & 0.695 & 0.408 & 0.012 & \\
\hline Group & 11.216 & 2 & 5.608 & 3.227 & 0.047 * & 0.103 & FES $<$ FIS \\
\hline Error & 97.335 & 56 & 1.738 & & & & \\
\hline \multicolumn{8}{|c|}{$R^{2}=0.141\left(\right.$ Adj $\left.R^{2}=0.095\right)$} \\
\hline Pre-test & 0.963 & 1 & 0.963 & 0.983 & 0.326 & 0.017 & \\
\hline Group & 4.163 & 2 & 2.082 & 2.126 & 0.129 & 0.071 & \\
\hline \multirow{2}{*}{\multicolumn{8}{|c|}{$R^{2}=0.095\left(\right.$ Adj $\left.R^{2}=0.046\right)$}} \\
\hline & & & & & & & \\
\hline \multicolumn{8}{|c|}{ P7 channel } \\
\hline Pre-test & 11.063 & 1 & 11.063 & 12.114 & 0.001 & 0.178 & \\
\hline Group & 17.945 & 2 & 8.973 & 9.825 & $0.000^{* *}$ & 0.260 & FES, FPS $<$ FIS \\
\hline Error & 51.140 & 56 & 0.913 & & & & \\
\hline \multicolumn{8}{|c|}{$R^{2}=0.417\left(\right.$ Adj $\left.R^{2}=0.386\right)$} \\
\hline \multicolumn{8}{|c|}{ P8 channel } \\
\hline Pre-test & 17.189 & 1 & 17.189 & 16.155 & 0.000 & 0.224 & \\
\hline Group & 5.030 & 2 & 2.515 & 2.364 & 0.103 & 0.078 & \\
\hline Error & 59.584 & 56 & 1.064 & & & & \\
\hline \multicolumn{8}{|c|}{$R^{2}=0.360\left(\operatorname{Adj} R^{2}=0.326\right)$} \\
\hline \multicolumn{8}{|c|}{ O1 channel } \\
\hline Pre-test & 6.419 & 1 & 6.419 & 9.717 & 0.003 & 0.148 & \\
\hline Group & 5.162 & 2 & 2.581 & 3.907 & $0.026 *$ & 0.122 & FES $<$ FIS \\
\hline Error & 36.994 & 56 & 0.661 & & & & \\
\hline \multicolumn{8}{|c|}{$R^{2}=0.293\left(\right.$ Adj $\left.R^{2}=0.255\right)$} \\
\hline \multicolumn{8}{|c|}{ O2 channel } \\
\hline Pre-test & 12.248 & 1 & 12.248 & 34.657 & 0.000 & 0.382 & \\
\hline Group & 2.418 & 2 & 1.209 & 3.420 & $0.040 *$ & 0.109 & FES $<$ FIS \\
\hline Error & 19.791 & 56 & 0.353 & & & & \\
\hline$R^{2}=0.494\left(\operatorname{Adj} R^{2}=0\right.$ & & & & & & & \\
\hline
\end{tabular}

Table A2. Effect of bamboo forest space on the mood state across the experimental groups (covariates: pre-tests; dependent variables: post-tests).

\begin{tabular}{|c|c|c|c|c|c|c|c|}
\hline Mood State & Sum of Squares & df & Mean Square & $\mathbf{F}$ & Sig. & Partial $\eta^{2}$ & $\begin{array}{c}\text { Pairwise } \\
\text { Comparisons }\end{array}$ \\
\hline \multicolumn{8}{|c|}{ Positive mood (score) } \\
\hline Pre-test & 495.228 & 1 & 495.228 & 14.540 & 0.000 & 0.206 & \\
\hline Group & 269.449 & 2 & 134.724 & 3.956 & $0.025 *$ & 0.124 & FES $>$ FPS \\
\hline Error & 1907.322 & 56 & 34.059 & & & & \\
\hline \multicolumn{8}{|c|}{$R^{2}=0.306\left(\operatorname{Adj} R^{2}=0.269\right)$} \\
\hline \multicolumn{8}{|c|}{ Negative mood (score) } \\
\hline Pre-test & 609.634 & 1 & 609.634 & 18.820 & 0.000 & 0.252 & \\
\hline Group & 106.774 & 2 & 53.387 & 1.648 & 0.202 & 0.056 & \\
\hline Error & 1814.016 & 56 & 32.393 & & & & \\
\hline \multicolumn{8}{|c|}{$R^{2}=0.256\left(\operatorname{Adj} R^{2}=0.216\right)$} \\
\hline \multicolumn{8}{|c|}{ TMD (score) } \\
\hline Pre-test & 535.184 & 1 & 535.184 & 5.918 & 0.018 & 0.096 & \\
\hline Group & 680.000 & 2 & 340.000 & 3.760 & $0.029 *$ & 0.118 & FES $<$ FIS \\
\hline Error & 5064.316 & 56 & 90.434 & & & & \\
\hline$R^{2}=0.168\left(\right.$ Adj $R^{2}=$ & & & & & & & \\
\hline
\end{tabular}

Note: Positive mood (vigour + self-esteem); negative mood (tension + anger + depression + fatigue + confusion); TMD (total mood disturbance) $=$ tension + anger + depression + fatigue-vigour + confusion-self-esteem +100 ; $* p<0.05$. 
Table A3. Effect of bamboo forest space on spatial scales across the experimental groups (dependent variables: post-tests).

\begin{tabular}{|c|c|c|c|c|c|c|c|}
\hline \multicolumn{2}{|c|}{ Spatial scales } & \multirow{2}{*}{$\begin{array}{l}\mathbf{N} \\
20\end{array}$} & \multirow{2}{*}{$\frac{\mathbf{M}}{12.90}$} & \multirow{2}{*}{$\frac{\text { SD }}{2.33734}$} & \multirow{2}{*}{$\frac{\mathbf{F}}{16.718}$} & \multirow{2}{*}{$\frac{\text { Sig. }}{0.000^{* *}}$} & \multirow{2}{*}{$\begin{array}{c}\text { Tukey's HSD } \\
\text { FES, FPS > FIS }\end{array}$} \\
\hline Total & FPS & & & & & & \\
\hline & FIS & 20 & 9.70 & 2.47301 & & & \\
\hline & FES & 20 & 13.40 & 1.69830 & & & \\
\hline \multirow[t]{3}{*}{ Width } & FPS & 20 & 2.50 & 0.88852 & 15.005 & $0.000^{* *}$ & FES, FPS > FIS \\
\hline & FIS & 20 & 1.75 & 0.91047 & & & \\
\hline & FES & 20 & 3.20 & 0.69585 & & & \\
\hline \multirow[t]{3}{*}{ Height } & FPS & 20 & 2.40 & 0.82078 & 1.585 & 0.214 & \\
\hline & FIS & 20 & 1.95 & 1.05006 & & & \\
\hline & FES & 20 & 2.40 & 0.88258 & & & \\
\hline \multirow[t]{3}{*}{ Distance } & FPS & 20 & 2.75 & 0.85070 & 1.562 & 0.219 & \\
\hline & FIS & 20 & 2.30 & 0.86450 & & & \\
\hline & FES & 20 & 2.40 & 0.82078 & & & \\
\hline \multirow[t]{3}{*}{ Density } & FPS & 20 & 2.45 & 0.82558 & 12.554 & $0.000^{* *}$ & FES, FPS > FIS \\
\hline & FIS & 20 & 1.35 & 0.74516 & & & \\
\hline & FES & 20 & 2.60 & 0.99472 & & & \\
\hline \multirow[t]{3}{*}{ Overall } & FPS & 20 & 2.80 & 0.76777 & 2.335 & 0.106 & \\
\hline & FIS & 20 & 2.35 & 0.98809 & & & \\
\hline & FES & 20 & 2.80 & 0.41039 & & & \\
\hline
\end{tabular}

Note: Total $=$ Width + Height + Distance + Density + Overall; $* * 0.01$.

\section{References}

1. Lin, W.; Chen, Q.; Jiang, M.; Zhang, X.; Liu, Z.; Tao, J.; Wu, L.; Xu, S.; Kang, Y.; Zeng, Q. The effect of green space behaviour and per capita area in small urban green spaces on psychophysiological responses. Landsc. Urban Plan. 2019, 192, 103637. [CrossRef]

2. Flouri, E.; Midouhas, E.; Joshi, H. The role of urban neighbourhood green space in children's emotional and behavioural resilience. J. Environ. Psychol. 2014, 40, 179-186. [CrossRef]

3. Jonker, M.F.; van Lenthe, F.J.; Donkers, B.; Mackenbach, J.P.; Burdorf, A. The effect of urban green on small-area (healthy) life expectancy. J. Epidemiol. Community Health 2014, 68, 999-1002. [CrossRef] [PubMed]

4. Bergmann, F.; Gregorius, H.R.; Kownatzki, D.; Wehenkel, C. Different diversity measures and genetic traits reveal different speciesgenetic diversity relationships: A case study in forest tree communities. Silvae Genet. 2013, 62, 25-37. [CrossRef]

5. Uddling, J.; Teclaw, R.M.; Kubiske, M.E.; Pregitzer, K.S.; Ellsworth, D.S. Sap flux in pure aspen and mixed aspen-birch forests exposed to elevated concentrations of carbon dioxide and ozone. Tree Physiol. 2008, 28, 1231. [CrossRef]

6. Gebauer, T.; Horna, V.; Leuschner, C. Canopy transpiration of pure and mixed forest stands with variable abundance of European beech. J. Hydrol. 2012, 442-443, 2-14. [CrossRef]

7. Chang, C.-Y.; Hammitt, W.E.; Chen, P.-K.; Machnik, L.; Su, W.-C. Psychophysiological responses and restorative values of natural environments in Taiwan. Landsc. Urban Plan. 2008, 85, 79-84. [CrossRef]

8. Park, B.-J.; Tsunetsugu, Y.; Kasetani, T.; Morikawa, T.; Kagawa, T.; Miyazaki, Y. Physiological effects of forest recreation in a young conifer forest in Hinokage Town, Japan. Silva Fenn. 2015, 43, 291-301. [CrossRef]

9. Chen, H.-T.; Yu, C.-P.; Lee, H.-Y. The Effects of Forest Bathing on Stress Recovery: Evidence from Middle-Aged Females of Taiwan. Forests 2018, 9, 403. [CrossRef]

10. Ochiai, H.; Ikei, H.; Song, C.; Kobayashi, M.; Miura, T.; Kagawa, T.; Li, Q.; Kumeda, S.; Imai, M.; Miyazaki, Y. Physiological and Psychological Effects of a Forest Therapy Program on Middle-Aged Females. Int. J. Environ. Res. Public Health 2015, 12, 15222-15232. [CrossRef]

11. Ohe, Y.; Ikei, H.; Song, C.; Miyazaki, Y. Evaluating the relaxation effects of emerging forest-therapy tourism: A multidisciplinary approach. Tour. Manag. 2017, 62, 322-334. [CrossRef]

12. Song, C.; Ikei, H.; Miyazaki, Y. Sustained effects of a forest therapy program on the blood pressure of office workers. Urban For. Urban Green. 2017, 27, 246-252. [CrossRef] 
13. Williams, K.J.H.; Cary, J. Landscape Preferences, Ecological Quality, and Biodiversity Protection. Environ. Behav. 2016, 34, 257-274. [CrossRef]

14. Lee, J.; Park, B.-J.; Tsunetsugu, Y.; Kagawa, T.; Miyazaki, Y. Restorative effects of viewing real forest landscapes, based on a comparison with urban landscapes. Scand. J. For. Res. 2009, 24, 227-234. [CrossRef]

15. Hassan, A.; Chen, Q.B.; Jiang, T.; Lyu, B.Y.; Li, N.; Li, S.; Shangguan, Z.Y.; Li, Y.T.; Jun, Z.L.; Luo, Q.; et al. Psychophysiological Effects of Bamboo Plants on Adults. Biomed. Environ. Sci. 2017, 30, 846-850. [CrossRef]

16. Chiang, Y.-C.; Li, D.; Jane, H.-A. Wild or tended nature? The effects of landscape location and vegetation density on physiological and psychological responses. Landsc. Urban Plan. 2017, 167, 72-83. [CrossRef]

17. Beili, Z. Brief introduction of POMS scale and its model for China. J. Tianjin Inst. Phys. Educ. 1995, 10, 35-37.

18. Kacha, L.; Matsumoto, N.; Mansouri, A. Electrophysiological Evaluation of Perceived Complexity in Streetscapes. J. Asian Archit. Build. Eng. 2015, 14, 585-592. [CrossRef]

19. Neale, C.; Aspinall, P.; Roe, J.; Tilley, S.; Mavros, P.; Cinderby, S.; Coyne, R.; Thin, N.; Bennett, G.; Thompson, C.W. The Aging Urban Brain: Analyzing Outdoor Physical Activity Using the Emotiv Affectiv Suite in Older People. J. Urban Health 2017, 94, 869-880. [CrossRef]

20. Zou, B.; Liu, Y.; Guo, M.; Wang, Y. EEG-Based Assessment of Stereoscopic 3D Visual Fatigue Caused by Vergence-Accommodation Conflict. J. Disp. Technol. 2015, 11, 1076-1083. [CrossRef]

21. Hsu, B.W.; Wang, M.J. Evaluating the effectiveness of using electroencephalogram power indices to measure visual fatigue. Percept. Mot. Ski. 2013, 116, 235-252. [CrossRef] [PubMed]

22. Kim, J.-Y.; Kim, J.-T.; Kim, W. Psycho-physiological responses of drivers to road section types and elapsed driving time on a freeway. Can. J. Civ. Eng. 2015, 42, 881-888. [CrossRef]

23. Watts, G.; Khan, A.; Pheasant, R. Influence of soundscape and interior design on anxiety and perceived tranquillity of patients in a healthcare setting. Appl. Acoust. 2016, 104, 135-141. [CrossRef]

24. Krzywicka, P.; Byrka, K. Restorative Qualities of and Preference for Natural and Urban Soundscapes. Front. Psychol. 2017, 8, 1705. [CrossRef] [PubMed]

25. Gehl, J. Life Between Buildings: Using Public Space; Island Press: Washington, DC, USA, 2011; p. 216.

26. Hall, E.T. The silent language; Anchor Books: New York, NY, USA, 1973; p. 217.

27. Lawson, B.R. The Language of Space. Nature 2007, 252, 93. [CrossRef]

28. Suh, Y.A.; Yim, M.-S. "High risk non-initiating insider" identification based on EEG analysis for enhancing nuclear security. Ann. Nucl. Energy 2018, 113, 308-318. [CrossRef]

29. Cahn, D.A.; Salmon, D.P.; Butters, N.; Wiederholt, W.C.; Corey-Bloom, J.; Edelstein, S.L.; Barrett-Connor, E. Detection of dementia of the Alzheimer type in a population-based sample: Neuropsychological test performance. J. Int. Neuropsychol. Soc. 1995, 1, 252-260. [CrossRef]

30. Gotts, Z.M.; Ellis, J.G.; Deary, V.; Barclay, N.; Newton, J.L. The association between daytime napping and cognitive functioning in chronic fatigue syndrome. PLoS ONE 2015, 10, e0117136. [CrossRef]

31. Daniel, T.C.; Boster, R.S. Measuring Landscape Esthetics: The Scenic Beauty Estimation Method; Res. Pap. RM-RP-167; U.S. Department of Agriculture, Forest Service, Rocky Mountain Range and Experiment Station: Fort Collins, CO, USA, 1976; p. 66.

32. Fredrickson, B.L.; Levenson, R.W. Positive Emotions Speed Recovery from the Cardiovascular sequelae of negative emotions. Cogn. Emot. 1998, 12, 191-220. [CrossRef]

33. Purcell, A.T.; Lambb, R.J. Preference and naturalness: An ecological approach. Landsc. Urban Plan. 1998, 42, 57-66. [CrossRef]

34. Jiang, B.; Larsen, L.; Deal, B.; Sullivan, W.C. A dose-response curve describing the relationship between tree cover density and landscape preference. Landsc. Urban Plan. 2015, 139, 16-25. [CrossRef]

35. Hartig, T.; Evans, G.W.; Jamner, L.D.; Davis, D.S.; Gärling, T. Tracking restoration in natural and urban field settings. J. Environ. Psychol. 2003, 23, 109-123. [CrossRef]

36. Song, C.; Joung, D.; Ikei, H.; Igarashi, M.; Aga, M.; Park, B.-J.; Miwa, M.; Takagaki, M.; Miyazaki, Y. Physiological and psychological effects of walking on young males in urban parks in winter. J. Physiol. Anthropol. 2013, 32, 18. [CrossRef] [PubMed]

37. Taylor, A.F.; Kuo, F.E. Children with attention deficits concentrate better after walk in the park. J. Atten. Disord. 2009, 12, 402-409. [CrossRef] 
38. Jiang, B.; Chang, C.-Y.; Sullivan, W.C. A dose of nature: Tree cover, stress reduction, and gender differences. Landsc. Urban Plan. 2014, 132, 26-36. [CrossRef]

39. Kaplan, R.; Kaplan, S.; Ryan, R.L. With People in Mind; Island Press: Washington, DC, USA, 1998.

40. Kaplan, R. The Nature of the View from Home: Psychological Benefits. Environ. Behav. 2016, 33, 507-542. [CrossRef] 